Volume and Issues Obtainable at Center for Sustainability Research and Consultancy
Journal of Business and Social Review in Emerging Economies
ISSN: 2519-089X (E): 2519-0326
Volume 6: Issue 2 June 2020
JSRᄃ
Journal homepage: www.publishing.globalcsrc.org/jbsee

\title{
A Systematic Review of Ontology-Based Approach and Decision-Making (DM) To Improve Public Service Delivery (PSD)
}

\author{
${ }^{1}$ Rozaina Ali, ${ }^{2}$ Ahmad Shaharudin Abdul Latiff, ${ }^{3}$ Sazali Abdul Wahab \\ ${ }^{1,2 \& 3}$ Putra Business School, Malaysia \\ rozaina.phd_mgt18@grad.putrabs.edu.my \\ shaharudin@putrabs.edu.my \\ sazali@putrabs.edu.my
}

\begin{tabular}{l}
\hline ARTICLE DETAILS \\
\hline History \\
Revised format: May 2020 \\
Available Online: June \\
2020
\end{tabular}

\section{Keywords}

Public Service Delivery; Ontology; Decision-making, Social Media Data, Web Data

JEL Classification M1, MO

\begin{abstract}
A systematic review of the DM literature on PSD was performed with the aim to build an operational ontology-based for decision makers. Five public administration journals were screened on the subject with more than 200 articles found. 29 articles were shortlisted, categorized, summarized, and applied to outline the influential factors in DM for PSD. The result of the systematic reviews also provided a brief clarification on the requirement for the creation of a more citizen-centric and coordinated eco-system for efficient PSD underpinned by effective DM.
\end{abstract}

Objective: The purpose of this paper is to analyses PSD of the government and presents efforts to better improve DM process in the PSD.

Methodology: To get a comprehensive overview of previous and current events within the subject of study, review of literatures between year 2010 and 2020 were collected which comprising current literature and documents in the subject of PSD, social media (SM) and web data. The data were interpretively analyzed.

Conclusion: Throughout the analysis, a focus has been on creation of a public sector service delivery (SD) framework and ecosystem adapting to different service areas, organizational boundaries and levels of government. Transparency of governments' operation consolidated of information as knowledge sharing and digital technologies for DM were discovered to be the important elements in relation to efficiency in PSD.

Implication: This research presented a conceptual framework that captured common concepts involved in the PSD by utilizing social media data and web data to improve DM process in relation to PSD. This paper provides recommendations on how PSD can be improved with effective DM using social media and web data.

(C) 2020 The authors, under a Creative Commons AttributionNonCommercial 4.0 
Corresponding author's email address: rozaina.phd_mgt18@grad.putrabs.edu.my

Recommended citation: Ali, R., Latif, S. A., and Wahab, S. A. (2020). A systematic review of ontology-based approach and decision-making (DM) to improve public service delivery (PSD). Journal of Business and Social Review in Emerging Economies, 6 (2), 629-640

\section{Introduction}

Efficient PSD is a main objective for every government. An important aspect of PSD is ensuring services provided fulfil the changing needs of the citizens. Abstractly, public service of any country is a foundation of governance and administration made essentially to furnish open with great necessities (water, electricity, healthcare, quality education and transportation frameworks among others) to the citizen in the most productive and successful strategy (Akintunde, 2018). Nowadays, the PSD is meant as the improvement of administration for better government that provides services benefiting the general public (Dudley, Lin, Mancini, \& Ng, 2015; Makareviciute, 2017). The services given to the public are not only provided by a single governmental agency but also involve inter and intra governmental agencies which may have complex structure and involve many stakeholders that can cause lack of coordination and conflict of interests (Khan, 2017; Kuitert \& Volker, 2013; Latiff, Haron, \& Annamalai, 2017; Loutas, Lee, Maali, Peristeras, \& Tarabanis, 2011) .

PSD has a significant role in accelerating human operation and reducing economic inequality in a country. Thus, in most of the developing countries, PSD is mandatory for the endurance and the growth of the organization (Akintunde, 2018; Majid et al., 2019; Shaikh, Shah, \& Wijekuruppu, 2016; World Bank Group, 2018). Numerous researchers have confirmed that there is a constructive and significant connection between PSD and performance in relation to economic development where good governance plays an importance role (Kalava, 2016; Nawi et al., 2017). In relation to this matter, one of the biggest challenges for the public sector in many developing countries is to achieve an effective PSD.

\subsection{Overview of PSD}

The public sector is rapidly changing. The needs to improve its administration would be to increase government's efficacy and capability in order to ensure the citizens receive the good service needed. A report on "Improving Public Sector Performance Through Innovation And Inter-Agency Coordination" by World Bank stated that to improve performance of public sector, it can be implemented in many ways such as consolidating outcome from the central government, administration of civil service, transformation in budgeting, delivering justice services and new approaches in last-mile SD (World Bank Group, 2018).

Public sector performance is showing a significant improvement across the developing nation today, as government authorities and political leaders discover new and inventive approaches to handle longstanding public administration challenges (Karim, 2015; Narasimhan, Pillai, Delivery, \& Specialist, 2018). This includes good governance of quality PSD, accountable-decision-making, and civic engagement that requires institutions serve all stakeholders within a reasonable and acceptable timeframe (Japheth, Ngigi, \& Sang, 2016; Mahajan-Cusack, 2016; MEA, 2018). Governance is the process of DM and how those decisions are implemented (Japheth et al., 2016). It means that institutions and processes produce results that satisfy the needs and meets the needs of society. DM requires knowledge which is usually characterised as a set of basic definitions known as options, criteria, decision matrix, and the decision itself. This knowledge must be formalised, appropriately structured and interlinked within a model (Bastinos \& Krisper, 2013; Kornyshova \& Deneckère, 2012). Hence, efficient PSD is the key agenda to every governments and it is important, especially for PSD to be reliable and dependable in order to gain the trust of the public and meet their expectations.

Several studies on improving the delivery of public services were carried out by scholars such as (Bradbury, 2018; Buranarach et al., 2018; Dalmau-Espert, Llorens-Largo, Compan-Rosique, Satorre- 
Cuerda, \& Molina-Carmona, 2016; Giest \& Raaphorst, 2018; Japheth et al., 2016; Ju, Liu, \& Feng, 2018; Leoi \& Chung, 2019; Mahajan-Cusack, 2016; Nielsen, 2019; Porumbescu, 2016). These researchers generally presented that there is critical need to enhance the productive and effective PSD by the government. In a similar way, studies have similarly indicated the utilization of various models for the delivery services by the governments (Brusa, Caliusco, \& Chiotti, 2006; Khalil \& Salihu, 2012; Ndevu \& Muller, 2017; Shaikh et al., 2016).

Moreover, information gap contributed to the cause of less responsiveness in government services due to most services are not linked within and across ministries and agencies; mainly due to the segregation way of functioning, incompatible systems or technologies rendered in agencies. This had cause lacking in providing timely information or services to the citizens (Husin, Saad, \& Othman, 2017; Japheth et al., 2016). SD also includes numerous stakeholders that are interrelated. It needs coordination of the several associated activities in relation to delivery of services. In addition, the services rendered by government are frequently involves several layers (repetitive) and must adhere to some procedure. This can occasionally lead to irregularity in practice and possible human judgment mistakes (Buranarach et al., 2018). Poor information governance was another factor identified that contributed to the irresponsiveness of government in PSD. This factor derived from lack of effective, consistent, and quality information needed for DM. As acknowledged by practitioners, it is central to the design of a customer-centric SD model the realisation that SD can be organised. To achieve this, breaking down governmental silos and moving towards a "whole-of- government" approach is needed (Ozols \& Nielsen, 2018).

\subsection{Objectives}

The aim of the review was to classify actionable DM activities that can improve its efficiency in relation to PSD. The review attempted to recognise or build concepts on government collected information from various sources that can be turned to knowledge artefacts for DM. Connection between DM process and knowledge artefacts that were classified as shared information within, or inter-government is an important connection in the logic framework of information governance in PSD.

\section{Literature Review}

\subsection{DM in PSD}

DM is a key action for management in any organisation. The procedure of DM includes settling on a decision from a lot of options. Today, many high-level procedures identified for DM are manually made. This is because the available information is frequently in the form of reports and pre-set data (DalmauEspert et al., 2016). Decision makers often inspect goals, values and criteria in assessing this set of choices. There are normally numerous, often conflicting, criteria that should have been accessed in DM. As government worldwide increasingly become digital, digital technology plays a large role in Malaysian government's SD. One of the pioneer initiatives was the establishment of Malaysian Public Complaints Bureau (PCB) in 1971 to ensure a fair and effective public administration and SD to the public (Majid et al., 2019). The urgency of transformation is intensified by factors such as increasing urbanisation, an ageing population and the need to reskill a large portion of the workforce to adapt to innovations in technology (Nor, 2018). The administration of public sector organisation has experienced considerable changes intended at conveying improved services in the efficiency and effectiveness due to the rise of global economy and technology, and increased societal needs (Husin et al., 2017; Siddiquee et al., 2017).

Information captured from outside sources that are relevant to the organisation will allow precise combination of datasets for DM where it permits decision makers to harvest interconnected information for analytics purpose (T.Izhar, Torabi, \& Bhatti, 2017). The information captured needs to be turned into knowledge in order to benefits from it. Therefore, along the process of securing knowledge, it is significant that both knowledge provider (source) and recipient have the same interest to share information where the management should overcome the silo mentality and encourage information 
sharing within departments (Obeidat et al., 2016).

Stein and Zwass (1995) have likewise featured that storage and retrieval of organisational knowledge which incorporates knowledge exist in various structure, for example, written records, documented managerial policies and measures, and organised knowledge stored in database, data warehouse or other business intelligence tools that are denoted as administrative memory. Hence, knowledge storage is the way of perceiving new information as relevant and essential for present and future use, where it must be stored and shared in sensible structures and accessible by anyone in the organization (Stein \& Zwass, 1995).

Providing quality information for the use of public services can significantly impact on the value of public services (Afridi \& Gulati, 2017). The shift of public sector organisations towards a digital-era governance play a wide-ranging series of transformation on how public services are planned and delivered to citizens. The effectiveness of the delivery system and good governance in the civil service will be the catalyst to achieve national agenda of a country, for example the Malaysia Shared Prosperity Vision 2030 (SPV 2030) (Bernama, 2019).

\section{Conceptual Framework}

Figure 1 was adapted from the "Latvian public service delivery governance and coordination framework" by Ozols \& Nielsen (2018) (Ozols \& Nielsen, 2018). For this review, the focus is on the "Shared Information" between "Steering and Coordination of Data" and "Implementation". As Karim (2015) explained, collaboration and shared information between ministries and agencies offers benefits of integrated government (Karim, 2015). Information gathered needs to be analysed in a structured manner where decision makers need to recognise all the business procedures that will be affected by each decision made (T.Izhar et al., 2017) and this information needs to be transformed into knowledge to gain benefits from it.

Therefore, the enhanced framework provides consolidation of data from several sources for more efficiency and effectiveness in DM. It contributes to governments' business process redesign and operations that lead to cost decrease, information and service retrieval enhancement, information and services more availability (anytime, anywhere), customer orientation and better security (Lopes \& Dhaou, 2018). With this, governments are moving towards data-driven DM which contributes to better improvement in PSD. Consolidated information also not only can feed DM but planning and policy making that can moreover serve as a follow-up tool, improving the implementation processes and the functioning of implementor organisations (OECD, 2017). 


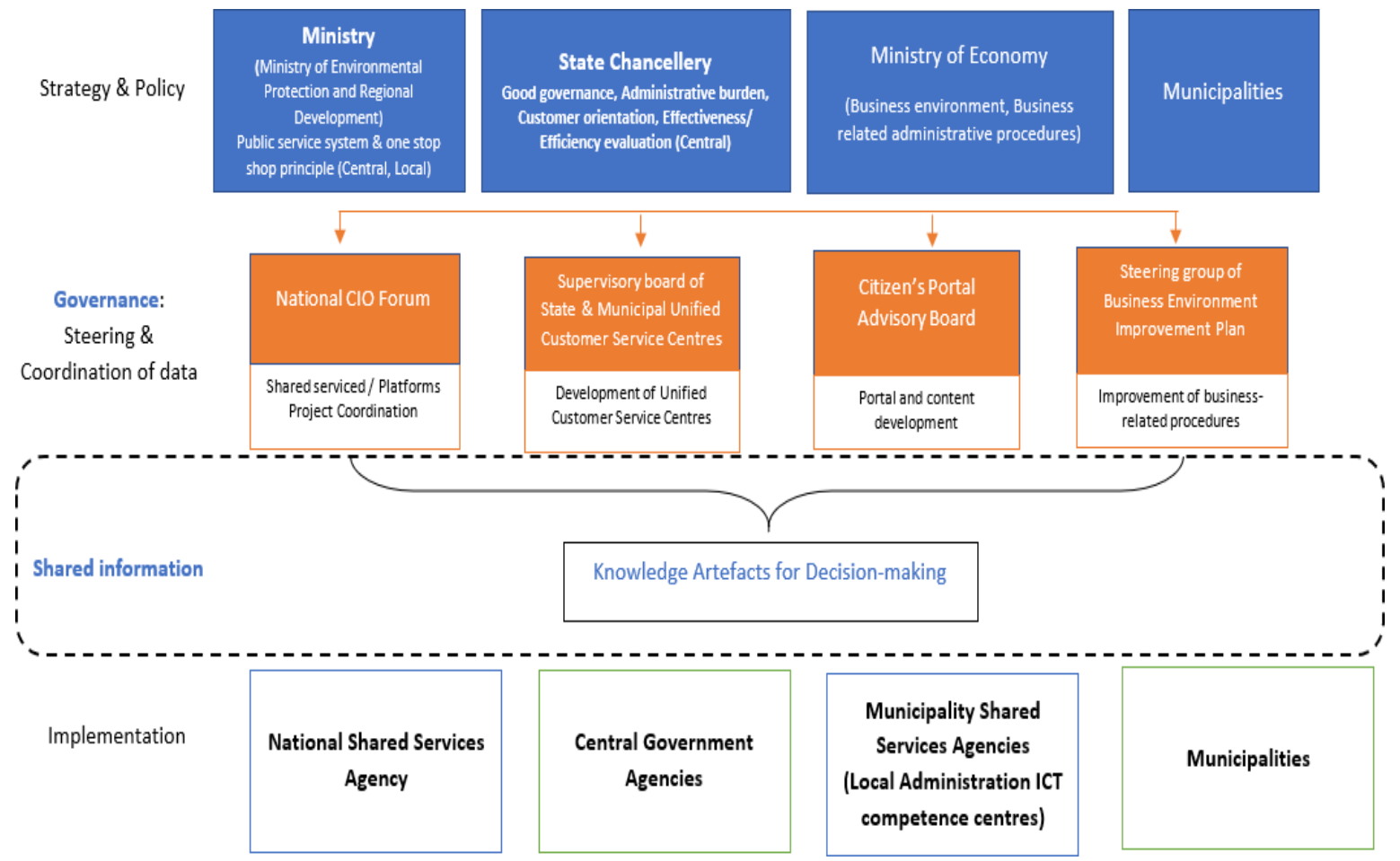

Figure 1: Conceptual Framework to formalise a common understanding for decision-making in public service delivery

\section{Methodology}

\subsection{Search Strategy}

Examinations were carried out under four topics; "ontology-based approach", "decision-making", "government" and "public service delivery". Records were identified through Scopus and Science Direct. Three top public administration journals websites were then examined; namely Public Administration Review, Journal of Public Administration Research and Theory, and Administration and Society, together with years the journal was published. All are in the main five rankings public administration journals (Schafer, 2018). To remove redundancy of articles searched because of the multiple search terms used, all titles were recorded in an excel file.

Other than top public administration journals websites, JSTOR search was adopted using a modified search strategy. Search was confined to "articles" with "English" as the language comprising Journal of Public Policy (2010-2020), Journal of Policy Analysis and Management (2010-2020), Publius (20102020), Public Administration Quarterly (2010-2020), Public Performance and Management Review (2010-2020), and State and Local Government Review (2010-2020). The search procedures implemented was to confirm that studies that exist in high quality peer-reviewed journals are counted in. An overview of the results of the search and screening method are presented in Figure 2. 


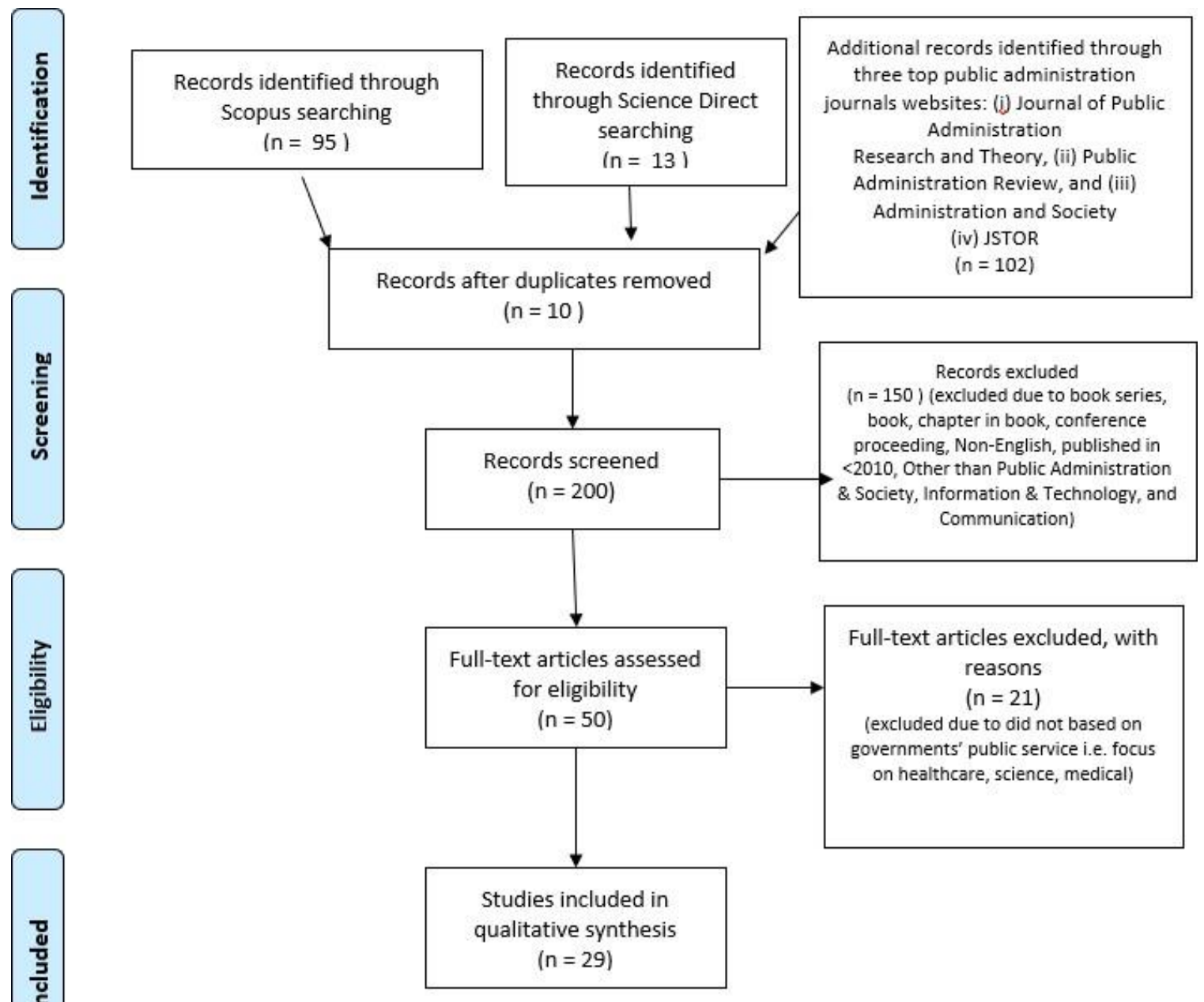

Figure 2 - Flow diagram of search and screening outcomes

\subsection{Study Screening and Selection}

210 articles were discovered from the search. The articles were initially marked for any duplication. Next, titles and abstracts of the articles were examined for its suitability of the focused topic in meeting the empirical requirement. The articles were reduced to $50(\mathrm{n}=50)$ where it was fully screened for the scale to which public service or DM was distinctly operationalised and considered as an outcome variable in the study. The study had to be able to demonstrate some influential factor in utilising social media and web data for DM. Finally, 29 articles were then coded and studied in the qualitative synthesis.

\section{Analysis and Discussions}

\subsection{Transparency of Public Operation}

The citizen needs communication as an essential tool to participation, which could be understood as public communication, to gain knowledge (Pieczka, 2019). Dixon (2010) explained on knowledge and truth in relation to human nature where human will make selections that they expect will benefits them, provided that they have complete and certain knowledge of, and the capability to compute the outcomes of the chosen alternative and varied courses of action. Thus, in DM, the honesty of a knowledge claim should be determined only by adopting objective truth criteria, which means that for a knowledge claim to be true, it must be with fact (Dixon, 2010). 
This coincide with Engin and Treleaven (2019) research on "Automating Public Services and Supporting Civil Servants in using Data Science Technologies"; where government data landscape is characterised by a multiple sources such as official records and census or statistics that are applicable in governments' operations and gives countless benefits for economic development, political, scientific and social innovations (Engin \& Treleaven, 2019). As such, there is a growing need to study the extent to governments operation that demands more in the responsibilities in data-work, particularly in terms of ethical data collection, methodological transparency and curation (Otero, José, \& Silva, 2012).

Furthermore, government information is mostly offered in heterogeneous formats, missing clear semantics that explain what the information portrays. The information likewise showed in manners that is not clearly reasonable to a broad range user network that need to make informed decisions. Other than that, as various organisations work in remoteness of one another, frequently the information that is gathered is stored in proprietary formats that are strictly combined with certain software and equipment used to gather, store and process. This implies the stored data is of limited use to other group except if they have that equivalent programming or software, causing the capacity and advantages for information re-use is either low or even non-existent. This can be especially problematic and expensive for governments as information and understanding that may be gleaned from that data to better inform policy decisions is not possible and for them to go out and collect the required data can be very expensive. The apparent resolution to this issue is for the information to be shared and accessible to others (McMeekin \& West, 2012). Moreover, merging of data grants knowledge transfer from one government organisation to others which in returns will aid the reduction of the uncertainty usually associated with the urban design process, thus removing speculations, assumptions and single perspective rationale from the decision process (Nisha \& Nelson, 2012).

\subsection{Predictive Analytics with Digital Technologies for DM}

$\mathrm{SM}$ data are part of $\mathrm{BD}$, which is a term that portrays data sets of huge size, gathered on and from individuals who are connected to technology. With such huge numbers of SM users, it is not astounding that researchers have started to understand its potential and utility as a plentiful and free source of data, particularly about how people learn, experience, create, share, and communicate. BD tools and methods brings benefit to the government and businesses in understanding the complexity of internet-based tools such as internet service by the internet service provider (ISP), search engine, and so forth that empower them to enhance their DM ability which finally provide them with better visual for future planned activities (Smith, 2013). However, when making decisions affecting public utility, public administrators need to depend on data and knowledge that supporting their decisions, which is useful to educate those citizens that will be affected by the decisions made (Di Mauro et al., 2016).

The accessibility of information has opened doors for data-driven analysis and DM. Combination of digital technologies and BD bring predictive analytics into picture that are giving huge impact to many professionals, individuals and even at the organisational level, national level and global (Fenwick \& Edwards, 2016). Digital technology and BD are part of the developing knowledge foundations in today's life, with the powerful networks of people, artefacts, and organisations that owned the data and gain benefits from the explicit knowledge shared.

Unfortunately, much of any organisation's knowledge exists in the form of unstructured resources such as project summary reports, research and development reports, etc. Transforming this unstructured knowledge into an electronically accessible form that can be integrated with their knowledge management system as well as decision support systems seems is an ideal solution hoped for by many organisations. This will help to overcome the vast quantity of documents to be processed and the lack of available expertise in knowledge extraction (Halder \& Knapp, 2013).

Another example on automation would be NSFC, known as the China's biggest government funding agency. Activity of categorising proposals was done manually according to research discipline areas, 
where selection of research projects is one of a repetitive activity in the organisation. The scientific department, the DM unit responsible for subsidising proposals understood that the decision process fails to be accurate. Later, a novel ontology-based text mining method was proposed to bunch proposals and overcome the inaccuracy issue (Preethi \& Lakshmi, 2013).

Even though knowledge is broadly accessible, whether knowledge is kept in companies' storage or over the web, humans have basic restrictions to process extremely huge volumes of data or to monitor regular updates in a continually evolving world. Consequently, DM is regularly based on rules of thumb rather than systematic analysis. This includes commissioning an intelligent system to support the cyber security protocols established in governments' or organisations' on-site premises or cloud computing for suitable DM, which may rely on the efficiency of knowledge representation (Asamoah, Tao, Gai, \& Jiang, 2016). Dedicated computer systems used to manage knowledge can explore range of options that could enhance DM by increasing human awareness of possible misunderstandings and biases (Cristina $\&$ Garcia, 2010). The key challenge is not data production anymore, yet data recovery and selection (generation of pertinent data), administration, use and display (Otero et al., 2012) which nowadays can be categorised as data governance.

\subsection{Ontologies to Support Information and Knowledge Sharing}

Numerous knowledge representation models use ontologies stereotypically to support examination, retrieval and sharing of information. The most commonly accepted and broadly used meaning for ontology is from Gruber (1993) (Gruber, 1993). Gruber gave meaning to ontology as "a specification of a representational conceptualization for a shared domain of discourse - definitions of classes, relations, functions, and other objects" (Chowdhury \& Zhu, 2019; Kamsu-Foguem, Abanda, Doumbouya, \& Tchouanguem, 2019; Maigua-Quinteros, Perez-Nata, Fernandez-Pena, \& Urrutia-Urrutia, 2018). Hence, An ontology can be assumed as a condition to demonstrate the knowledge of a specific domain be represented, described, structured and shared (Balduccini et al., 2019; Kamsu-Foguem et al., 2019) due to its ability in promoting sharing of knowledge bases, knowledge organization, and interoperability among systems (Chowdhury \& Zhu, 2019).

Lack of efficient communication mechanisms inhibits the success of government efficiency in DM (Slaviero, Garcia, \& Maciel, 2011). Ontologies are utilised for example in the e-government area in encouraging interoperability among governmental systems, providing services and trading information. Web ontologies help knowledge sharing for programmes and human beings. Among others, it helps local governments on georeferenced data for the recovery planning during catastrophic events or supporting the endorsement of cultivation zones based on the evaluation of soil pollution (MaiguaQuinteros et al., 2018). Arsovski et al., (2018) proposed ontology model that gave advantages which were achieved by using DM procedure that eliminates the subjective reasoning of the managerial staff and decision proposals which were justified in state development strategies (Arsovski, Markoski, Petrov, Stanisavljev, \& Zakin, 2018). Additionally, Aritonang et al., (2017) successfully modelled ontology and semantic network of regulation of the minister of finance concerning customs and excise which can further be developed to build interface using software that can facilitate all users to search the regulations of customs and excise (Aritonang, Seminar, Wahjuni, \& Purbo, 2017).

\section{Conclusion}

The main objective of the systematic review carried out in this paper was to develop an actionable ontology-based for decision makers that demonstrate the importance of information sharing in PSD. Over 200 articles, in five public administration journals were examined on the topic. The findings from 29 articles were shortlisted, categorised, summarised, and applied to outline the influential factors in DM for PSD. The result of the systematic reviews also provided a brief clarification on the requirement for the creation of a more citizen-centric and coordinated eco-system for efficient PSD underpinned by effective DM. 
Throughout the analysis, a focus has been on transparency of governments' operation, consolidation of information as knowledge artefacts in DM and options that are available as solution enabling the creation of a public sector SD framework and ecosystem adapting to different service areas, organisational boundaries and levels of government. The main findings derived from the analysis can be summarised as follows:

i. The analysis finds a tendency towards centralisation of shared information derived from multiple government agencies for more consistent and coordinated data governance across different agencies and levels of government for DM. The aim of the coordination and integration via standard methods promote greater collaboration among agencies, interoperability and shared technology for operational efficiency and transparency.

ii. Measuring and exposing performance data is crucial to enables responsible service providers to assess the efficiency, effectiveness and quality levels of their service portfolio and delivery channels over time. The operational data can also be aggregated and is essential for policymakers to make evidence-based and informed strategic decisions.

iii. For enhancing the PSD, need to encourage the practice of accountability in public service providers, monitoring and evaluating performance and outcome of the services provided to public. Specific strategy on PSD must be formulated based on the needs of public rather than executing planned development only and resource savings.

iv. To include in DM priority of coordination between all government levels to accomplish greater levels of inclusion, transparency and smooth delegation of function towards better performance of SD.

\section{References}

Afridi, F., \& Gulati, N. (2017). Governance and public service delivery in India. The International Growth Centre, India.

Akintunde, O. (2018). Governance and Public Service Delivery in Nigeria: The Role of Information and Communication technologies CUCEN2017. (September).

Aritonang, E. M., Seminar, K. B., Wahjuni, S., \& Purbo, O. W. (2017). Modeling ontology and semantic network of regulations in customs and excise. Telkomnika (Telecommunication Computing Electronics and Control), 15(4), 1934-1942. https://doi.org/10.12928/TELKOMNIKA.v15i4.6590

Arsovski, S., Markoski, B., Petrov, N., Stanisavljev, S., \& Zakin, M. (2018). Ontology of the development strategies: The basis for decision support in government development funds. Tehnicki Vjesnik, 25(3), 898-903. https://doi.org/10.17559/TV-20160209130040

Asamoah, C., Tao, L., Gai, K., \& Jiang, N. (2016). Powering Filtration Process of Cyber Security Ecosystem Using Knowledge Graph. Proceedings - 3rd IEEE International Conference on Cyber Security and Cloud Computing, CSCloud 2016 and 2nd IEEE International Conference of Scalable and Smart Cloud, SSC 2016, (1), 240-246. https://doi.org/10.1109/CSCloud.2016.36

Balduccini, M., Griffor, E., Huth, M., Vishik, C., Wollman, D., \& Kamongi, P. (2019). Decision support for smart grid: Using reasoning to contextualize complex decision making. 7th Workshop on Modeling and Simulation of Cyber-Physical Energy Systems, MSCPES 2019 - Held as Part of CPS Week, Proceedings, 1-6. https://doi.org/10.1109/MSCPES.2019.8738798

Bastinos, A. Š., \& Krisper, M. (2013). Multi-criteria decision making in ontologies. Information Sciences, 222, 593-610. https://doi.org/10.1016/j.ins.2012.07.055

Bernama. (2019). Agensi kerajaan perlu lebih pantas dalam penyampaian perkhidmatan.

Bradbury, P. (2018). Challenges faced by the public sector. Retrieved from https://www.openaccessgovernment.org/challenges-faced-by-the-public-sector/53751/

Brusa, G., Caliusco, M. L., \& Chiotti, O. (2006). Building ontology in public administration: A case study. CEUR Workshop Proceedings, 226, 16-30.

Buranarach, M., Anutariya, C., Kalayanapan, N., Ruangrajitpakorn, T., Wuwongse, V., \& Supnithi, T. (2018). An ontology-based approach to supporting knowledge management in government agencies: A case study of the Thai excise department. IEICE Transactions on Information and 
Systems, E101D(4), 884-891. https://doi.org/10.1587/transinf.2016IIP0001

Chowdhury, S., \& Zhu, J. (2019). Towards the ontology development for smart transportation infrastructure planning via topic modeling. Proceedings of the 36th International Symposium on Automation and Robotics in Construction, ISARC 2019, (Isarc), 507-514.

Cristina, A., \& Garcia, B. (2010). AGUIA: Agents guidance for intelligence amplification in goal oriented tasks. Proceedings - International Conference on P2P, Parallel, Grid, Cloud and Internet Computing, 3PGCIC 2010, 338-344. https://doi.org/10.1109/3PGCIC.2010.56

Dalmau-Espert, J. L., Llorens-Largo, F., Compan-Rosique, P., Satorre-Cuerda, R., \& Molina-Carmona, R. (2016). Leveraging information for high level-of-Abstraction organizational processes. International Journal of Design and Nature and Ecodynamics, 11(3), 416-427. https://doi.org/10.2495/DNE-V11-N3-416-427

Di Mauro, F., Pasteris, P., Sapino, M. L., Candan, K. S., Dino, G. A., \& Rossetti, P. (2016). Crowd sourced semantic enrichment for participatory e-government. 8th International Conference on Management of Digital EcoSystems, MEDES 2016, 82-89. https://doi.org/10.1145/3012071.3012102

Dixon, J. (2010). Symposium The Dismal (Delusional and Dangerous) "Science" of Economics and the "Capture" of Public Administration: Naive Neoclassical Economics and the Promised Land of Privatization. Administrative Theory \& Praxis, 32(3), 348-372. https://doi.org/10.2753/atp10841806320304

Dudley, E., Lin, D.-Y., Mancini, M., \& Ng, J. (2015). Implementing a citizen-centric approach to delivering government services. McKinsey Insights, (July 2015), 3-9.

Engin, Z., \& Treleaven, P. (2019). Algorithmic Government: Automating Public Services and Supporting Civil Servants in using Data Science Technologies. Computer Journal, 62(3), 448-460. https://doi.org/10.1093/comjn1/bxy082

Giest, S., \& Raaphorst, N. (2018). Unraveling the hindering factors of digital public service delivery at street-level: the case of electronic health records. Policy Design and Practice, 1(2), 141-154. https://doi.org/10.1080/25741292.2018.1476002

Gruber, T. R. (1993). Toward Principles for the Design of Ontologies Used for Knowledge Sharing.

Halder, A., \& Knapp, G. M. (2013). Automatic extraction of ontology from technical journals. IIE Annual Conference and Expo 2013, 224-230.

Husin, R., Saad, R., \& Othman, Z. . (2017). E-kerajaan: tinjauan dan perlaksanaanya di Malaysia. Journal of Technology and Operations Management, 12(2), 7-14.

Japheth, L., Ngigi, M., \& Sang, A. (2016). Citizens 'Perceptions On The Status Of Governance ( Public Service Delivery) In The Counties: The Case Of Migori County , Kenya. 21(6), 29-32. https://doi.org/10.9790/0837-2106082932

Ju, J., Liu, L., \& Feng, Y. (2018). Citizen-centered big data analysis-driven governance intelligence framework for smart cities. Telecommunications Policy, 42(10), 881-896. https://doi.org/10.1016/j.telpol.2018.01.003

Kalava, I. V. (2016). Factors Influencing Service Delivery at the County Government: a Case of Kakamega County.

Kamsu-Foguem, B., Abanda, F. H., Doumbouya, M. B., \& Tchouanguem, J. F. (2019). Graph-based ontology reasoning for formal verification of BREEAM rules. Cognitive Systems Research, 55, 1433. https://doi.org/10.1016/j.cogsys.2018.12.011

Karim, M. R. A. (2015). Technology and improved service delivery : learning points from the Malaysian experience. 69(September 2002), 191-204.

Khalil, S., \& Salihu, A. (2012). Model for Efficient Service Delivery in Public Service. (July). https://doi.org/10.5296/jpag.v2i3.2157

Khan, G. F. (2017). Social Media for Government. Social Media for Government, 7-21. https://doi.org/10.1007/978-981-10-2942-4

Kornyshova, E., \& Deneckère, R. (2012). Using an Ontology for Modeling Decision-Making Knowledge Using an Ontology for Modeling Decision-Making Knowledge. (May). https://doi.org/10.3233/9781-61499-105-2-1553 
Kuitert, L., \& Volker, L. (2013). Public Service Delivery in Hybrid Organisations public management reform and horizontalisation as main challenges for public leaders.

Latiff, A. S. A., Haron, H., \& Annamalai, M. (2017). Characteristics and development criteria for Islamic banking ontology. 2016 3rd International Conference on Information Retrieval and Knowledge Management, CAMP 2016 - Conference Proceedings, (September 2018), 136-142. https://doi.org/10.1109/INFRKM.2016.7806350

Leoi, S. L. (The S. O., \& Chung, C. (The S. O. (2019). World Bank: Efficiency of Malaysia's civil service has stagnated.

Lopes, N. V., \& Dhaou, S. Ben. (2018). Public service delivery framework: Case of Canada, China and Estonia. ACM International Conference Proceeding Series, 101-110. https://doi.org/10.1145/3209415.3209489

Loutas, N., Lee, D., Maali, F., Peristeras, V., \& Tarabanis, K. (2011). The semantic public service portal (S-PSP). Lecture Notes in Computer Science (Including Subseries Lecture Notes in Artificial Intelligence and Lecture Notes in Bioinformatics), 6643 LNCS(PART 2), 227-242. https://doi.org/10.1007/978-3-642-21064-8_16

Mahajan-Cusack, L. (2016). The impact of social media on local government transparency and citizen engagement. The State University of New Jersey, (May), 166. Retrieved from https://rucore.libraries.rutgers.edu/rutgers-lib/50539/

Maigua-Quinteros, A., Perez-Nata, W., Fernandez-Pena, F., \& Urrutia-Urrutia, P. (2018). Fostering Exploration of Georeferenced Data Semantics for Supporting E-government Initiatives. 2018 5th International Conference on EDemocracy and EGovernment, ICEDEG 2018, 223-228. https://doi.org/10.1109/ICEDEG.2018.8372363

Majid, M., Samad, S., Danial, M., Tazilah, A. K., Farhana, N., Suffari, S. @, ... Khamar, A. (2019). Human Capital, Service Delivery and Public Service Effectiveness and Efficiency: a Preliminary Study. International Journal of Business and Technology Management, 1(1), 35-45. Retrieved from http://myjms.mohe.gov.my/index.php/ijbtm

Makareviciute, B. R. (2017). How digital can bring better government.

McMeekin, D. A., \& West, G. (2012). Spatial data infrastructures and the semantic web of spatial things in Australia: Research opportunities in SDI and the semantic web. International Conference on Human System Interaction, HSI, 197-201. https://doi.org/10.1109/HSI.2012.36

MEA. (2018). Mid-term review of the Eleventh Malaysia Plan 2016-2020.

Narasimhan, A. T., Pillai, A., Delivery, P. S., \& Specialist, T. (2018). A Paradigm Shift in Public Service Delivery: 2(5), 114-138.

Nawi, N. B. C., Mamun, A. Al, Nasir, N. A. B. M., Shokery, N. M. bt A. H., Raston, N. B. A., \& Fazal, S. A. (2017). Acceptance and usage of social media as a platform among student entrepreneurs. Journal of Small Business and Enterprise Development, 24(2), 375-393. https://doi.org/10.1108/JSBED-09-2016-0136

Ndevu, Z., \& Muller, K. (2017). A Conceptual Framework for Improving Service Delivery at Local Government in South Africa. 9(7), 13-24.

Nielsen, M. M. (2019). Tackling identity management, service delivery, and social security challenges : technology trends and partnership models. 1-5.

Nisha, B., \& Nelson, M. (2012). Making a case for evidence-informed decision making for participatory urban design. Urban Design International, 17(4), 336-348. https://doi.org/10.1057/udi.2012.16

Nor, M. H. M. (The E. (2018). MySay: Achieving successful and sustainable public sector reform.

Obeidat, B. Y., Hashem, L., Alansari, I., Tarhini, A., Al-Salti, Z., Hashem, L., ... Tarhini, A. (2016). The Effect of Knowledge Management Uses on Total Quality Management Practices: A Theoretical Perspective. Journal of Management and Strategy, 7(4), 18-29. https://doi.org/10.5430/jms.v7n4p18

OECD. (2017). Draft Policy Framework on Sound Public Governance. Retrieved from http://www.oecd.org/gov/draft-policy-framework-on-sound-public-governance.pdf

Otero, N., José, R., \& Silva, B. (2012). On the Move to Meaningful Internet Systems: OTM 2012 Workshops. Lecture Notes in Computer Science (Including Subseries Lecture Notes in Artificial 
Intelligence and Lecture Notes in Bioinformatics), 7567(October 2014), 617-626. https://doi.org/10.1007/978-3-642-33618-8

Ozols, G., \& Nielsen, M. M. (2018). Connected Government Approach for Customer-centric Public Service Delivery: Comparing strategic, governance and technological aspects in Latvia, Denmark and the United Kingdom. (December), 58.

Pieczka, M. (2019). Looking back and going forward: The concept of the public in public relations theory . Public Relations Inquiry, 8(3), 225-244. https://doi.org/10.1177/2046147x19870269

Porumbescu, G. A. (2016). Linking public sector social media and e-government website use to trust in government. Government Information Quarterly, 33(2), 291-304. https://doi.org/10.1016/j.giq.2016.04.006

Preethi, T., \& Lakshmi, R. (2013). An implementation of clustering project proposals on ontology based text mining approach. 2013 International Conference on Information Communication and Embedded Systems, ICICES 2013, 547-550. https://doi.org/10.1109/ICICES.2013.6508288

Schafer, J. G. (2018). A systematic review of the public administration literature to identify how to increase public engagement and participation with local governance. (June), 1-11. https://doi.org/10.1002/pa.1873

Shaikh, A. Z., Shah, U. L., \& Wijekuruppu, C. (2016). Public Service Delivery and e-Governance: The Case of Pakistan National University of Science and Technology, Pakistan. 9(2), 1161-1170.

Siddiquee, N. A., Xavier, J. A., Mohamed, M. Z., Alam, N., Antony, J., \& Zin, M. (2017). What Works and Why? Lessons from Public Management Reform in Malaysia What Works and Why? Lessons from Public Management Reform in Malaysia. International Journal of Public Administration, OO(00), 1-14. https://doi.org/10.1080/01900692.2017.1390762

Slaviero, C., Garcia, A. C. B., \& Maciel, C. (2011). Towards an ontology to support the deployment of eParticipation environments. Lecture Notes in Computer Science (Including Subseries Lecture Notes in Artificial Intelligence and Lecture Notes in Bioinformatics), 6866 LNCS, 146-160. https://doi.org/10.1007/978-3-642-22961-9_12

Smith, M. (2013). Theses on the philosophy of history: The work of research in the age of digital searchability and distributability. Journal of Visual Culture, 12(3), 375-403. https://doi.org/10.1177/1470412913507505

Stein, E. W., \& Zwass, V. (1995). Actualizing organizational memory with information systems. Information Systems Research, 6(2), 85-117. https://doi.org/10.1287/isre.6.2.85

T.Izhar, T. A., Torabi, T., \& Bhatti, M. I. (2017). Using Ontology to Incorporate Social Media Data and Organizational Data for Efficient Decision - Making. (February).

World Bank Group. (2018). Improving Public Sector Performance through Innovation and Inter-Agency Coordination. 